\title{
Las tecnologías avanzadas de la información y la comunicación (TIC) y el nuevo paradigma temporal
}

\author{
Maria Dolores Ayuso García \\ Professora titular de fontes de informação da Faculdad de \\ Documentación da Universidad de Murcia - Espanha. \\ E-mail:mayu@um.es
}

\section{Antonio Parra}

Jornalista. Professor doutor da Faculdad de Comunicación y Documentación da Universidad de Murcia - Espanha. E-mail: aparra@um.es

\section{Resumen}

Se presenta el paradigma temporal desde la perspectiva actual de la sociedad de la información y el conocimiento. Se analiza el tiempo virtual en el ámbito de las TIC. Se estudia el tiempo en los medios de comunicación y la oferta de "tiempo real", lo inmediato, en la sociedad global y su relación con las demandas de información de los usuarios y ciudadanos. Se propone un esfuerzo ético y de transparencia en plena era global y en un mundo marcado por las tecnologías y el tiempo de la información.

\section{Palabras clave}

Chat; E-mail; Duración del tiempo; Fuentes informativas; Globalización de la información; Información y comunicación; Mundialización; Nuevas tecnologías; Periodismo; Tiempo real; Tiempo de información.

\section{Advanced information technologies and communication and the new time paradigm}

\begin{abstract}
We present the temporal paradigm from the current perspective of the Information and Knowledge Society. We analyse the virtual time in the sphere of ICT. We study the time in the media and the offer of "real time", of what it's immediate, in a Global Society, as well as their relationship with information requests made by users and citizenship. A call is made for an ethic and transparency effort in a totally global age and within a world which is marked by IT and information time.
\end{abstract}

\section{Keywords}

Chat; E-mail; Duration ofthe time; Informative sources; Globalization of the information; Information and communication; Global world; New technologies; Journalism; Real time; Information time.

\section{INTRODUCCIÓN}

Aunque en la actualidad Internet: los chats, el correo electrónico, nos hagan hablar y escuchar constantemente que esta o aquella información se ha obtenido en "tiempo real", el tiempo es quizás uno de los conceptos más escurridizos, pero también de los más convencionales. Al intentar definir el tiempo evocamos siempre las palabras de San Agustín en sus Confesiones (XI, 14): ".Qué es, pues, el tiempo? Si nadie me lo pregunta lo sé, pero si trato de explicárselo a quien me pregunta, no lo Sé”*. La paradoja planteada por el obispo de Hipona nos descubre que el tiempo es una percepción genuinamente humana: de un lado, una intuición del sujeto cognoscente en sentido kantiano, que pone sentido en el aparecer de los fenómenos particulares introduciendo espacio y tiempo; de otro lado es una convención humana para poner orden en un espacio y tiempo infinitos incapaz de dominar. En las llamadas sociedades pre-racionales el hombre delimitaba (marcaba un limes) a través de la ritualización del tiempo y del espacio: los templos, los lugares sagrados, las fiestas y efemérides circulares, situaban a la tribu, marcaban ellimes propio, como forma de establecer un orden. Es éste, precisamente, un tiempo antiguo, opuesto por algunos autores - como enseguida veremos - al tiempo propio de la información, que es no sólo un tiempo moderno, genuinamente histórico e ilustrado, sino también de la actualidad, del discurrir diario marcado por la comunicación cotidiana o por la información periodística. El primero se constituye bajo el paradigma de la duración; el segundo, bajo el de la inmediatez.

En la actualidad el par tiempo / información se ha visto transformado por la confluencia de las TIC, que sin duda, y como afinna Negroponte, están modificando también las fuentes, creando "...el potencial de un nuevo contenido, originado a partir de una combinación totalmente nueva de las fuentes" en general y de las fuentes informativas en particular. Los factores tecnológicos, determinados por una tecnología intensa en innovación y velozmente cambiante, son los factores responsables de un nuevo posicionamiento en el binomio información / tiempo, que también afecta al

\footnotetext{
* Biblioteca de Autores Cristianos. La traducción de José Cosgaya recoge estas palabreas de S. Agustín. Publicado en Madrid en 1988.
} 
almacenamiento y a la recuperación de la información, aunque no es éste el tema objeto de nuestro trabajo.

Cabe entonces preguntarse es que el tiempo es algo existente, que está ahí fuera, como un algo objetivo, ralentizándose o acelerándose según los casos? Lo que ocurre es que nuestra percepción del tiempo ha variado a lo largo de la historia. Esa convención trascendental que es el tiempo ha venido a marcar, con un rito o con un reloj, la vida de los hombres. No podemos demoramos ahora en una historia del tiempo. Baste, para nuestras pretensiones en este trabajo, marcar esas dos características fundamental (duración y velocidad) de los tiempos antiguo y actual.

Una de las maneras posibles de abordar la información es a través del tiempo, de su tiempo. La información tiene tiempo. El concepto de la información es muy amplio, se encuentra en la base de todo conocimiento humano. Bien que barajemos una noció intemalista o extemalista (realista), es decir, que consideremos que existe un receptor previo que recoge la información del mundo, o por el contrario, sea que consideremos que la información se encuentra potencialmente en el mundo, al margen de la existencia o no de un receptor ${ }^{*}$, lo cierto es que la contemplación, la mirada al mundo, es la fuente de todo nuestro conocimiento; asimismo es fuente de conocimiento esa parte del mundo que son 'los otros', con los que intercambiamos información, diálogos; los otros, con quienes enfrentamos nuestros respectivos logos: logos contra logos, dialogos, con intercambio de información, de conocimiento mutuo. La información se encuentra igualmente en la base de la ciencia y de los metalenguajes.. Así, una teoria matemática de la comunicación establecerá la cantidad de información que transporta una señal aunque no qué información es transportad - delimitando así la medida de información adecuada para el trabajo científico, sobre todo en el ámbito de la ingeniería**.

De otro lado, a partir de los años 80, nuevos modelos tecnológicos y conceptuales han provocado una modificación en el posicionamiento de los agentes que operan en las prácticas informativas, principalmente debido a:

1. Una nueva visión conceptual de la información se relaciona con el conocimiento con el desarrollo humano.

2. Un desarrollo acelerado de la microelectrónica y de sus tecnologías paralelas.

\footnotetext{
* Pérez Gutiérrez, M. defiende una concepción realista y, por lo tanto, inocente, del fenómeno de la información en esta obra.

** Pérez Gutiérrez, M: Op. cit.
}

3. Un desarrollo acelerado de las telecomunicaciones y de sus tecnologías subordinadas. Así la Sociedad de la Información se constituye en el 2000 en Sociedad del Conocimiento.

Pero de nuevo tenemos que ir centrando el objetivo de este trabajo, abandonando consecuentemente el continuo ramaje que se va abriendo a cada paso en cuanto nos asomamos a ese balcón casi sin rondo que es el territorio de la información/comunicación. Vamos a hablar aquí del tiempo concreto de la información en el sentido de los medios, que se refiere, en parte, a la información periodística, que en este comienzo de un nuevo milenio viene caracterizada por las tecnologías avanzadas que afectan de manera sustancial a este campo. Vivimos en una era paradigmáticamente caracterizada como era de la información *, así como por la aceleración de la información, incluida, claro, la propiamente periodística, la de los medios de masas, como parte del mundo de la vida, por utilizar una expresión habermasiana.

Lo que intentaremos aquí será establecer la diferenciación entre el tiempo antiguo, marcado por la ritualización de la sociabilidad, y por el mito - el gran relato - como narración simbólica de la constitución de la tribu, frente al tiempo moderno marcado por la inmediatez, por la noticia. Tras establecer esa oposición entre las dos concepciones del tiempo mostraremos como las tecnologías avanzadas de la información y la comunicación [TIC], con su consecuente globalización, están forzando un nuevo paradigma temporal que, paradójicamente, en algún sentido, nos devuelve a un tiempo pre-histórico con su pretensión - más allá incluso de la lentitud antigua - de anular el tiempo*.

\section{EL TIEMPO DE LA DURACIÓN}

Quizás pocos como Walter Benjamin viesen con mayor lucidez el papel de los nuevos medios de reproducción masiva surgidos con fuerza a comienzos del siglo XX. Es especialmente conocido y citado su ensayo La obra de arte en la época de su reproductibilidad técnica. Pero toda su filosofia del lenguaje, y especialmente su filosofia de la historia (y no sólo la contenida en las célebres "Tesis...") está impregnada del concepto de duración. No es ahora el momento, lógicamente, de detenemos en la visión de Benjamin de la historia o dellenguaje. Pero sí insistiremos brevemente en su análisis de esa duración en el relato

\footnotetext{
* Castells, M., especialmente, vol. 1: "La sociedad red".

** Para Javier Pérez Royo, la cuestíón de los derechos de los ciudadanos ante los cambios tecnológicos en la información es muy interesante la ponencia presentada al CONGRESSO NACIONAL DE ANABAD, 7., 1999.
} 
(género de un 'tiempo antiguo') frente al fetiche de la actualidad que fascina a las sociedades mediáticas, y que en los anos en los que él comenzaba a escribir con plena madurez (décadas de los veinte y los treinta) ya asomaba su faz más agresiva, refutando cierta ingenuidad anterior, que encontraba en estos modernos medios la simbolización de los nuevos tiempos de progreso indefinido, felices y liberadores. En su ensayo "El narrador", (y en otros incluidos en sus Iluminaciones) el escritor judío subraya - más que un continuum histórico de tiempo - tres estratos sucesivos que se corresponderían, respectivanlente, con el relato oral (propio de la Edad Media), la novela (género propio de la burguesía que surge con potencia en la Modemidad, y tras las épocas de las sucesivas revoluciones europeas) y la prensa, como 'síntoma' de las sociedades actuales. El dibujo sucesivo de estos géneros muestra una pérdida paulatina del concepto - sin duda emocional y psicológico - del concepto de duración. En el relato oral, las vivencias - tanto en su vertiente de relato traído por el viajero que viene de lejos y porta "noticias" del exterior, como en la historia narrada por el relator sedentario que, en simbólico círculo de oradores y oyentes, narra, quizás arquetípicamente, el 'sentido' de esa comunidad permanecen. Lo que el viajero trae es asumido como propio por la comunidad, queda interiorizado, mientras que lo que narra el sedentario, que pennanece apegado a su círculo tribal o a su entorno, también se convierte en relato mítico, fuera de todo tiempo, lejano, como misteriosamente fundacional de esa comunidad.

De lo que habla Benjamin, según creernos, es de una interiorización de las cosas. Lo que se cuenta ha sido vivido, asumido, interpretado en el seno de cada comunidad. El relato, por extravagante que sea, "se entreteje con la propia vida sin necesidad de explicaciones, abriendo la puerta a lo maravilloso", tal como señala Rafael García Alonso comentando el ensayo citado de Benjamin. Enriquece en suma nuestra experiencia vital logrando hacer próximo lo distante, pero no como lo consiguen las modernas tecnologías de la comunicación, no porque el mundo sea una 'aldea global', sino por un proceso de maduración, como poso interior, como verdadera experiencia vivida.

A esas características del relato, ya debilitadas en el género de la novela, se oponen las propias de la prensa, surgida, según Benjamin, "en la fase del alto capitalismo como un instrumento de la filosofia dominante". Por el contrario, la prensa anula la distancia temporal en su obsesión por dar cuenta de lo "actual" Aunque la prensa atienda a lo ocurrido en cualquier punto de la tierra, ese círculo enorme es presentado como lineal y próximo gracias a la pretensión de que las noticias sean "verificadas de inmediato" (Benjamin: Sobre el programa de la filosofia futura). La prensa busca "lo plausible" (ibidem), lo que necesita de "explicaciones" (ibidem). Explicar algo implica situarlo en un curso sucesivo en el que un elemento da cuenta de otros en la sucesión del tiempo. Citando de nuevo a García Alonso, "a lo maravilloso del relato no había que preguntarle ni de dónde procedía ni su por qué; por eso, la prensa en su pretensión absolutamente opuesta lo anula corno posible". Se configura así un hombre carente de receptividad para las"...historias extraordinarias...”*. En su ensayo Experiencia y pobreza, Benjamin sentencia que "...nos hemos hecho pobres. Hemos ido entregando una porción tras otra de la herencia de la humanidad (...) a cambio de la pequena moneda de lo "actual".

De esta manera, y puesto que la experiencia se asentaba en la tradición, la urgencia de lo novedoso supone una “...atrofia creciente de la experiencia...".Triunfa de nuevo lo impersonal y ambiguo frente a lo personal y auténtico. Y la gran precariedad: “...época de la máxima alienación de los hombres entre sí, de las relaciones infinitamente mediatizadas, que son las únicas que tienen...".

La profesora Eva Aladro Vico** , que ha analizado también la visión de Benjamin sobre el tiempo en los distintos géneros literarios, establece un sustancioso paralelismo entre el filósofo judío y la escritora y pensadora Simone Weil, sobre todo en tomo a la teoria de la recepción de esa última, que en última instancia conlleva un silencio - el silencio es para Aladro Vico 'arte' de la comunicación, pues ésta "abarca” el silencio: "La comunicación es aquello que, dado el silencio, vence al silencio"***, que es atención, humildad, y que se identifica también con la actitud mística. Esta idea enlaza con los estudios de Benjamin sobre la pérdida de aura del arte moderno, pues esa pérdida de sacralidad del arte de las vanguardias tendría el mismo origen que el olvido de la duración frente a la velocidad contemporánea simbolizada por el periodismo. Vanguardias artísticas y periodismo serían, en fin, paradigmas expresivos de un tiempo que ha perdido su espacio sagrado, en el sentido de Weber.

\section{EL TIEMPO PERVERTIDO}

Aparentemente todo esto queda demasiado "filosófico", demasiado lejano de los problemas y consecuencias de las actuales sociedades mediáticas y, más en concreto,

\footnotetext{
* García Alonso, ibid.

** AlADRO VICO, E. Véase su obra teoría de información y la comunicación efectiva. Madrid : Fragua, 1998.

*** Ibídem. Aladro Vico, E.
} 
de la nueva crítica - desde posiciones éticas - al papel dominante y poderoso de la prensa actual, de cara a ir determinando la posibilidad de un control por parte de los ciudadanos, en primer lugar - pero también de lo filósofos políticos y de los sociólogos de la información - de ese nuevo poder emergente (el segundo, lo llama, ya sin tapujos, Margarita Riviére en un reciente libro de entrevistas*. Sin embargo no es así. El teórico de información Vicente Romano escribe lo siguiente:

"En el contexto de la comunicación, mediatizar sacar alguien de la inmediatez de la comunicación a través de contactos elementares, la adicción, contradicción y signos primarios, y someterlo por tiempo indefinido a sistemas mediales heterodeterminados. Estos tienen una estructura monológica, no dialógica. Un puñado de propietarios de los medios intenta ocupar al mismo tiempo el biotiempo irrecuperable del mayor número posible de personas en los espacios más amplios posibles. Hearst, Murdoch, Berlusconi, Polanco, etc., dominan a la perfección el principio asambleario"**.

Romano cita también al filósofo francés Henri Bergson, quien distinguía entre "temps" (tiempo) y "duree" (duración), esto es, entre tiempo objetivo medido con el reloj y tiempo vivido (subjetivo). La diferencia reside, sobre todo, en la distinta velocidad con que parece pasar el tiempo. "Esta diferencia constituye una experiencia cotidiana"***. Las consecuencias éticas son más graves de lo que pueda pensarse en un primer momento:

"Ante esta situación ay quien, como el norteamericano Jerry Mander, aboga por la supresión de la TV, por pagar la caja tonta y volver a la comunicación primaria, a las experiencias directas, no mediadas. Pero la psicóloga alemana Hertha Sturm, que desde en fin de la II Guerra Mundial viene investigando los efectos de los medios, en particular los audiovisuales, opina que ya no se puede apagar el televisor"****.

Y hablando del ordenador, hoy príncipe mecánico en cualquier ámbito de la vida laboral y hasta personal, indica el autor: "Si los ordenadores van a tomar decisiones en cuestión de nanosegundos, más allá de la conciencia humana, esos acontecimientos jamás podrá experimentarlos el ser humano. El tiempo del ordenador representa entonces la abstracción final del tiempo y su total separación de la experiencia humana y de los ritmos

\footnotetext{
* RIVIÉRE, M. El segundo poder. Madrid : El País-Aguilar, 1998.

** ROMANO, V. El tiempo y el espacio en la comunicación: la razón pervertida. Guipuzcoa : Argitaletxe Hiru, 1998, p. 99.

*** Ibidem, p. 247 .

**** Ibid, p. 403.
}

de la naturaleza. El tiempo evolutivo se ha convertido así en instantáneo"*.

En resumen, el hombre, el ciudadano, el usuario mediático, deja de ser dueño de su tiempo. Y en paradoja perversa, las tecnologías que "acelaran" nuestra vida, y que se convierten en eficaces instrumentos para los fines mercantiles de las empresas, y que en última instancia, según divisa sociológica que ha hecho fortuna en los últimos tiempos, liberan al hombre y lo destinan a una sociedad del ocio, acaban quitando al hombre su verdadero tiempo. En realidad el usuario de esas tecnologías habla de "falta de tiempo". El hombre moderno, en su conjunto, sigue hablando de falta de tiempo. La trampa habría sido perfecta. El hombre ha perdido su tempo, su pálpito interior, posado y rico en experiencias, en dia-logos social, en imbricación en su entorno social. Y a cambio ni siquiera ha ganado ese tiempo fugaz y vacío del ocio moderno, que, si acaso, consiste en sumergirse más y más en ese círculo vicioso mediático: jugar con ordenadores, navegar solitariamente en la realidad virtual de Internet, ver televisión o dejarse bombardear por una información que ya no puede asimilar, juzgar, analizar. Las guerras modernas son un buen ejemplo de todo esto. Una multinacional de la información televisiva, la CNN, tiene su eslogan en la frase: "Está pasando, lo estás viendo". Y el tiempo en Internet es inmediato, tiempo real. Pero, en realidad, en el fondo, ya no sabemos lo que está pasando, no tenemos más que una serie de imágenes, eso sí, inmediatas, urgentes, pasadas bajo el fetiche del aquí y ahora, pero que no entendemos del todo.

\section{LAS FUENTES INFORMATIVAS Y EL TIEMPO DEL PERIODISMO}

Sin embargo, el periodismo no renuncia a la 'duración' a su manera, y pese a moverse en el terreno fugaz de la información cotidiana, del día a día, la información periodística no es 'flor de un día', La teoria de la información se ocupa también del estudio del tiempo en ésta. Lorenzo Gomis** llama la atención sobre el hecho de que los medios tienden a titular en presente. Es una manera de provocar en lector u oyente la ilusión de que aquella noticia que te llega en ese momento está ocurriendo, efectivamente, en ese instante, y no ayer o anteayer, como en realidad sucede. Como las noticias, a través de tos periódicos diarios o por medio de los informativos de emisoras radio y canales de televisión,

\footnotetext{
* Ibid, p. 428 .

** GOMIS, L. Teoría del periodismo: cómo se forma el presente, 1a reimpresión. Madrid : [s. n.], 1997. Barcelona : Paido, 1991.
} 
se ofrecen cada día al usuario de la información, la sensación que se da es la de un 'presente' continuo siempre estamos en el hoy, en el ahora - cuando de lo que de verdad nos habla esa información es del tiempo que pasa, que ha de ser renovado continuamente por el nuevo tiempo que llega y que, a su vez, nos trae otras novedades que hacen olvidar a las del día anterior. De todas formas esta tendencia a hacer comparecer en presente lo que ocurrió ayer, hace unos días o, al menos, hace unas horas, no es exclusiva de los medios de comunicación, sino que estos extraen dellenguaje cotidiano. Para Garst y Bernstein* esa costumbre esta tomada de conversación corriente, del habla cotidiana. El presente se emplea porque es el tiempo lo inmediato, porque es más vívido y porque cuando la gente cuenta algo que le ocurrió y le conmovió mucho, tiende a contarlo en presente (Gomis, 97).

Pero además, la noticia no suele apagarse ni desaparecer de la memoria del ciudadano con el fulgor momentáneo de su publicación. Gomis ha fijado incluso la ración del eco de .una noticia en el ciudadano, que la mantiene viva, dependiendo, claro está, del interés que esa noticia haya despertado en la opinión pública. Porque "los medios no hacen historia y por eso algo que fuera enteramente pasado y no tuviera influencia ninguna en lo que hacemos o podemos hacer aquí y ahora no encontraría en los medios"**. Los medios "median entre el pasado y el futuro convirtiendo los los tiempos en presente e invitándonos a actuar en ese tiempo difuso, imaginado como un presente abierto al porvenir. El tiempo de la información es el presente, pero lo que consolida ese tiempo, lo amplia y da lugar a la reflexión y a la puesta en común de las impresiones es el comentario. El comentario fija la actualidad en la mente del público, que además interviene en la acción, a modo de coro, a través del comentario de los hechos que fonnan el presente social"***.

A juicio de Gomis, por lo tanto, "el presente de las noticias no se define tanto por su emisión como por su comentario"****. Y es que, aunque frente a un tiempo antiguo, hoy los mensajes aparecen y desaparecen a gran velocidad, "la extensión del presente no es una cuestión puramente física, sino simbólica”****.

\footnotetext{
* GARST, Q.; BERNSTEIN, T. Headlines and deadlines. Columbia :

Columbia University, 1961.

** Gomis, L., op. cit., p. 32.

**** Ibidem.

$* * * *$ Ibidem, p. 33

***** Ibidem.
}

Hay noticias que duran muy poco en ia memoria del receptor. Pero eso ocurre porque, desde la lógica periodística, desde el 'espíritu' del informador, no se trataba de una verdadera 'noticia', profesionalmente no se produjo una buena 'selección' de la realidad, de los hechos, de la actualidad. Una 'verdadera' noticia puede llegar a durar - es decir, puede ser presente - incluso durante toda una semana. En palabras de Gomis: "Las noticias influyen en los seres humanos mientras éstos las comentan. Que una noticia siga presente en los comentarios y en la memoria de los que tratan de dar cuenta de lo que pasa una semana después de haber desaparecido de los medios significa que siguen siendo noticia mientras se siga comentando, mientras se trabe conversación en tomo de ello, mientras no se haya acabado de entender ni de olvidar. Por eso son más noticia las noticias que más duran, porque son las que dan consistencia a nuestro presente de referencia, a nuestro presente colectivo, común, a los hechos que comentamos socialmente"**.

\section{EL TIEMPO DE LA ETERNIDAD}

Ahora bien, el tiempo del que habla Gomis y otros teóricos de la información se refiere al periodismo tradicional, al de la era de la sociedad de masas. Sin embargo, tal vez las nuevas formas de producción y apropiación de la información podrían representar el fin del ciclo de la cultura de masas. La cultura del paradigma del broadcast. Después de la ampliación del concepto de periodismo por efecto de la aparición de los medios audiovisuales y del protagonismo social creciente de los procesos de gestión de la información ${ }^{* * *}$, el periodismo digital está empezando a romper las variables de espacio y tiempo que hasta ahora habían enmarcado y dado sentido al trabajo periodístico. ${ }^{* * *}$

Las nuevas tecnologías de la información tratan de familiarizarnos con el fetiche de la velocidad, de la rapidez, de lo instantáneo incluso. Algunos importantes canales televisivos de noticias responden a esta lógica. La CNN - cadena especializada en un tipo de noticia que pretende ser global, universal, basada consecuentemente en fogonazos breves y de poca hondura argumental y explicativa, eminentemente visual,

** Ibidem, p. 33-34

*** AYUSO GARCIA, M. D. La globalización de la información y los derechos de los ciudadanos en los umbrales del s. XXI. In: CONGRESO NACIONAL DE AMABAD, 1999, Toledo. Actas... Toledo, 1999. p. 642-650. (Boletin, 49).

**** GOMEZ MOMPART, J. L.; MARIN OTTO, E. De los nuevos reporteros al periodismo digital. In: periodismo universal. Madrid : Síntesis, 1999. 
encerrados en noticiarios de no más de diez minutos tiene su principal eslogan en la creación de ese fetiche: 'Está pasando, lo estás viendo', dice su propia publicidad, corno hemos recordado anteriormente.

Parecería pues que nos alejamos más y más de aquella cultura de la duración de la que hablábamos al principio de este trabajo citando al filósofo alemán Walter Benjamin. Sin embargo, la Red, los satélites, la televisión por cable, en suma, los nuevas tecnologías, que nos hacen introducir en esa ilusión de la velocidad fabrican sus propias paradojas. Recientemente el gran filólogo y medievalista catalán Martín de Riquer, llamaba la atención sobre un aspecto del uso del ordenador: la posibilidad, a través de él, de la lentitud*. Dada su avanzada edad, el insigne erudito comenta al periodista que ya no investiga, pues no se encuentra en condiciones de ir a la Biblioteca a remover legajos. El entrevistador llama la atención sobre la posibilidad del uso de Internet, que "puede ayudarle sin salir de casa”. Martín de Riquer responde entonces lo siguiente: "En Internet no me he metido. Pero sí quiero hacer un elogio del ordenador. [...] El ordenador tiene la ventaja de que lo que has escrito lo puedes cambiar de orden, corregir y retocar todo lo que quieras. Ustedes los periodistas lo ven corno un instrumento para conseguir ia rapidez. No se dan cuenta de que la gracia del ordenador es la lentitud, detenerse, volver a mirar un texto, perfeccionarlo".

Un aspecto paradójico de uno de los juguetes de la nueva era de la información, el correo electrónico - que aliado con Internet parecía destinado a acabar con el papel (acabar con el papel es el deseo - amenaza lanzada por el 'gigante' Bille Gates ante el director de la Real Academia Española de la Lengua, en la visita de negocios que realizó a la institución española en 1999), y que también está modificando el concepto de Colegio

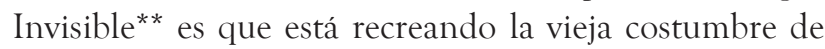
la epístola. El correo electrónico está sustituyendo en parte al teléfono, que a su vez estaba acabando con la carta manuscrita. Es cierto que por el momento las misivas en la Red suelen limitarse, en su extensión y contenidos, a despachos de negocios, a mensajes breves o al popular 'chateo', sin que pueda hablarse de la alta literatura que con frecuencia encerraban los antiguos epistolarios entre escritores o artistas. Sin embargo, es posible que todo se ande con el tiempo, y de momento

\footnotetext{
* Entrevista en el suplemento 'Domingo' del diario El País, 5 de noviembre de 2000.

** AYUSO GARCIA, M. Revisión interdisciplinar y fuentes de información en los umbrales del siglo XXI. Nuevas perspectivas: los recursos de información y documentación. Revista General de Información y Documentación, v. 9, n. 1, 1999, p. 203-215.
}

ya comienzan a comercializarse novelas enteras a través de Internet* ${ }^{*}$ de autores tan conocidos como Arturo Pérez Reverte y Sthefen King. También los foros de discusión como ejemplo de verdaderos encuentros científicos entre expertos de diversas disciplinas que engrandecen y multiplican lo no convencional o literatura gris.

Es decir, que unos medios vienen a superponerse sobre otros, pero no necesariamente a sustituirse. "La emergencia de estas nuevas formas de gestión profesional de la información pública de utilidad social no significará la desaparición de las ya denominadas fonnas de periodismo 'tradicional', El eco sistema comunicativo se ha constituido por lógica de acumulación y acomodación: un nuevo medio o una nueva modalidad comunicativa redefine las anteriores al delimitar su espacio $* *$.

Sin embargo, la gran paradoja provocada por las tecnologías de la información y la comunicación [TIC] sea tal vez el modo en que éstas orientan el tiempo. Ya hemos visto como el ordenador puede, curiosamente, devolvemos a una 'lentitud' olvidada bajo los paradigmas imperantes desde la Revolución Industrial. Pero es que la lógica de la instantaneidad de los nuevos medios puede acabar siendo como una última metáfora de la quietud total, de la anulación del tiempo. De manera brillante escribe Manuel Castell: "Propongo la idea de que el tiempo atemporal, como he denominado a la temporalidad dominante en nuestra sociedad, se da cuando las características de un contexto determinado, a saber, el paradigma informacional y la sociedad red, provocan una perturbación sistémica en el orden secuencial de los fenómenos realizados en ese contexto. Esta perturbación puede tomar la forma de condensar la secuencia de los fenómenos con el fin de lograr la instantaneidad, o también introducir una discontinuidad aleatoria en la secuencia. La eliminación de la secuenciación crea un tiempo indiferenciado, que es equivalente a la eternidad"***.

Naturalmente, Castell habla de esa nueva temporalidad informativa con amargura, o al menos con escepticismo, dado que, [y éste seria uno de los efectos indeseables de la globalización], "sin embargo, esta caracterización no hace referencia a todo el tiempo de la experiencia humana. De hecho, en nuestro mundo, la mayoría de la

\footnotetext{
* Por ejemplo, la última novela dedicada por Arturo Pérez-Reverte a las aventuras de su personaje Alatriste, en "El oro de1 rey"o también, con anterioridad la obra de Sthephen King "Riding the bullet". www.clarin.com/diario/2000- 07 -21/s -05301.htm

** Gómez Mompart y Marín Otto,_op. cit., p. 263.

*** Castell, M., op. Cit., p. 542 .
} 
gente y la mayoría de los espacios viven en una temporalidad diferente"*.

La vía ahora anunciada por Castell como 'tiempo atemporal' podría tener como metáfora última la del 'Grau hermano', ahora caída en el descrédito como consecuencia de su utilización por detenninados programas televisivos de gran audiencia. El último movimiento de la secuencia - de la lógica de la sociedad Red - seria la de una inmensa cámara que no solamente fuese capaz de mostramos imágenes de todo el mundo en minutos o incluso segundos, o simplemente en directo, sino demostramos el movimiento entero de la tierra sin otra explicación que su visión directa. $Y$ en última instancia sólo habría una câmara que gracias a su gran potencia captaria la ti erra en su totalidad, y a través de esa ventana podríamos observar a cada instante la totalidad de los hechos dei mundo. La paradoja o la ironía final es que, gracias a esa instantaneidad, gracias a esa velocidad', se habría vuelto a la quietud circular de un tiempo antiguo y sin historia.

Sabido es, por la teoria de la información, que un exceso de información puede ser contrainformativo, puede provocar un choque que haga eliminar la posibilidad misma de la información. De hecho - y al margen de la posibilidad improbable, por ahora, de esa película de terror que sería una potente cámara fija gracias a la cual todos nos observaríamos a todos - ya se está produciendo ese choque. Todos recordamos la Guerra del Golfo. Se ha dicho que fue la primera guerra de la historia televisada casi en directo. Sin embargo, todavía hoy, a diez anos de su finalización, seguimos teniendo más dudas que certezas sobre aquel odioso conflicto. Y es que mirar, ver sin más, no es suficiente; la acumulación de hechos, de noticias, no supone necesariamente más información, y a veces, si esa acumulación de actualidad es interesada resulta incluso contraproducente.

Para finalizar, y frente a los apocalípticos contra la globalización y contra las nuevas tecnologías de la información, hemos de indicar que queda, como siempre, el factor humano. Hoy como ayer sólo un renovado espíritu ilustrado, que haga de la información un arma contra la superstición y el oscurantismo, convertirá a las nuevas tecnologías en herramientas útiles para el progreso humano, y evitará que éstas se conviertan en una pesadilla contemporánea o bien en una perversa máquina que impulsa diferentes 'velocidades' en la tierra, creando una especie de primer, tercer y hasta cuarto mundo de la información.

* Ibidem, p. 543.
Con el fenómeno de la mundialización aparecen nuevos retos que afectan localmente a la filosofia ética, al Derecho y a las diferentes administraciones. Cuestiones como los derechos de autor en la Red, el respeto a la intimidad o una nueva delimitación entre lo público y lo privado exigen un renovado esfuerzo moral y legal. La información publicada surge como institución a lo largo del siglo XVII, pero se conforma a lo largo del siglo XVIII bajo un espíritu ilustrado. El esfuerzo ético y el ansia de transparencia que inspiró al movimiento del iluminismo debe perdurar hoy, en plena era global, y en un mundo marcado por las tecnologías y el tiempo de la información.

\section{Artigo recebido em 06-08-2004 e aceito para publicação de} 18 a $21 / 10 / 2004$.

\section{REFERÊNCIAS}

AYUSO GARCIA, M. D. La globalización de la información y los derechos de los ciudadanos en los umbrales del s. XXI. In: CONGRESO NACIONAL DE AMABAD, 1999, Toledo. Actas... Toledo, 1999. p. 642-650. (Boletin, 49).

Revisión interdisciplinar y fuentes de información en los umbrales del siglo XXI. Nuevas perspectivas: los recursos de información y documentación. Revista General de Información y Documentación, v. 9, n. 1, 1999, p. 203-215.

BENJAMIN Walter. Angelus novus. Barcelona : Edhasa, 1971.

Discursos interrumpidos. Madrid : Taurus, 1973.

Iluminaciones. Madrid : Taurus, 1998. v. 4.

CASTELLS, M. La era de la información. Madrid : Alianza, 1999. v. 3.

GARCIA ALONSO, R. El narrador y su red. In: BENJARMN, Walter. Ensayos sobre literatura filosófica. Madrid : Siglo XXI de España, 1995.

GARST, Q.; BERNSTEIN, T. Headlines and deadlines. Columbia : Columbia University, 1961.

GOMEZ MOMPART, J. L.; MARIN OTTO, E. De los nuevos reporteros al periodismo digital. In: periodismo universal. Madrid : Síntesis, 1999. (Ed.). Historia del

GOMIS, L. Teoría del periodismo: cómo se forma el presente, 1a reimpresión. Madrid : [s. n.], 1997. Barcelona : Paido, 1991.

HABERMAS, J. Teoría de la acción comunicativa. Madrid : Taurus, 1998. p. 551-572. v. 2.

NEGROPONTE, N. El mundo digital. Barcelona : Ediciones B, 1995, p. 33.

PÉREZ GURIÉREZ, Gutiérrez M. El fenómeno de la información: una aproximación conceptual al flujo informativo. Madrid, [s. n.], 2000.

PÉREZ ROYO, Javier. Información y derechos de los ciudadanos. In: CONGRESSO NACIONAL DE ANABAD, 7., 1999, Toledo. Actas... Toledo, 1999. p. 19-34.

RIVIÉRE, M. El segundo poder. Madrid : El País-Aguilar, 1998.

ROMANO, V. El tiempo y el espacio en la comunicación: la razón pervertida. Guipuzcoa : Argitaletxe Hiru, 1998, p. 99.

SHANNON, Claude; WEAVER, Warren. The mathematical theory of communication. Urbana : University of Illinois, 1981. Trad. do español: Teoria Matemática de la Comunicación, Madrid, 1981. 